\title{
Quatro diferentes visões sobre o estágio supervisionado
}

\author{
MICAÍAS ANDRADE RODRIGUES \\ Universidade Federal do Piauí, Teresina, PI, Brasil
}

\section{INTRODUÇÃO}

Há muito tempo existe uma reflexão sobre a formação de professores, com grande destaque para o pensamento de Comenius, no século XVII. E de lá para cá muita coisa mudou. Saviani (2009) faz um apanhado histórico acerca da formação de professores e comenta que no Brasil a questão do preparo desses profissionais emerge de forma explícita após a independência, quando se cogita a organização da instrução popular. O autor citado faz uma divisão ao longo desses dois séculos do que ele separou como sendo seis períodos na história da formação de professores no Brasil. Dentro dessa temática, iremos nos deter no que diz respeito aos estágios supervisionados durante os cursos de formação de professores em nível superior, as licenciaturas.

Para isso, conheceremos quatro diferentes vozes que estão envolvidas diretamente nos estágios supervisionados de ensino. A primeira voz será a legal, verificada com base no que é regido pela legislação vigente no Brasil sobre o estágio. A segunda voz será obtida pelo pensamento de alguns teóricos da atualidade sobre o que é o estágio supervisionado e qual a sua função. A terceira voz será a dos alunos que estão em formação inicial, matriculados na disciplina estágio supervisionado. A última voz será a dos professores colaboradores, aqueles que recebem e supervisionam os estagiários nas escolas. Ao fazermos essa verificação, poderemos obter uma visão mais completa acerca do estágio supervisionado e assim compreender se essas diferentes vozes envolvidas nesse momento essencial para a formação dos futuros professores estão ou não em sintonia entre si. Então teremos condições de 
propor alternativas para que esse momento seja realizado da maneira mais proveitosa, para obtermos como resultado profissionais mais capacitados e aptos para a atuação nas salas de aula.

\section{A LEGISLAÇÃO ACERCA DO ESTÁGIO SUPERVISIONADO}

A profissão docente é historicamente desvalorizada no Brasil: escolas sem condições salutares de abrigar alunos e profissionais da educação; baixos salários; amplas jornadas de trabalho; mau preparo docente etc. São vários os fatores que fazem os cursos de licenciatura serem esvaziados ou terem uma grande evasão.

Para tentar reverter esse quadro, algumas leis, pareceres e decretos foram promulgados no intuito de oferecer melhores condições para a atuação do docente, tanto durante a sua atuação como profissional habilitado, com destaque para a Lei do Piso Nacional do Professor (lei n. 11.738, de 16 de julho de 2008; Brasil, 2008a), que institui o piso salarial profissional nacional para os profissionais do magistério público da educação básica, quanto durante a sua formação em nível de graduação, com a Lei do Estágio (lei n. 11.788, de 25 de setembro de 2008; Brasil, 2008b), que dispõe sobre o estágio de estudantes, e o parecer n.28/2001 (Brasil, 2002), que estabelece a duração e a carga horária dos cursos de formação de professores da educação básica em nível superior, curso de licenciatura e de graduação plena. São nas duas últimas regulações que iremos nos deter.

Partiremos primeiramente da definição de estágio que a lei n. 11.788/2008 apresenta em seu artigo 10: "Estágio é ato educativo escolar supervisionado, desenvolvido no ambiente de trabalho, que visa à preparação para o trabalho produtivo de educandos que estejam frequentando o ensino regular [...]", acrescentando em seus incisos que o estágio faz parte do projeto pedagógico do curso e visa ao aprendizado de competências próprias da atividade profissional e à contextualização curricular, objetivando o desenvolvimento do educando para a vida cidadã e para o trabalho (Brasil, 2008b).

O parecer n. 28/2001 (Brasil, 2002) coloca um ponto-final na confusão entre as cargas horárias exigidas nas legislações anteriores para a prática de ensino e o estágio supervisionado. A Lei de Diretrizes e Bases (LDB) (lei n. 9.394, de 20 de dezembro de 1996; Brasil, 1996) é clara em seu artigo 65, quando diz que "A formação docente, exceto para a educação superior, incluirá prática de ensino de, no mínimo, trezentas horas". Mas dada a importância da prática na formação profissional de docentes, consideradas as mudanças em face do paradigma vigente até a entrada em vigor da nova LDB, percebeu-se que esse mínimo de horas estabelecido em lei não seria suficiente para dar conta de todas as exigências, especialmente da associação entre teoria e prática, tal como posto no artigo 61 da LDB.

Tendo isso em vista, o parecer n. 28/2001, em articulação com o novo paradigma das diretrizes, com as exigências legais e com o modelo de qualidade que deve existir nos cursos de licenciaturas, determina que sejam acrescentadas mais cem horas ao mínimo legal das já trezentas horas, para que se ampliem as possibilidades 
e aumente o tempo disponível para cada prática escolhida no projeto pedagógico do curso. "As trezentas horas são apenas o mínimo abaixo do qual não se consegue dar conta das exigências de qualidade. Assim torna-se procedente acrescentar ao tempo mínimo já estabelecido em lei (300 horas) mais um terço (1/3) desta carga, perfazendo um total de 400 horas" (Brasil, 2001b).

O citado documento (Brasil, 2002) especifica que é preciso considerar outro componente curricular obrigatório integrado à proposta pedagógica:

estágio curricular supervisionado de ensino entendido como o tempo de aprendizagem que, através de um período de permanência, alguém se demora em algum lugar ou ofício para aprender a prática do mesmo e depois poder exercer uma profissão ou ofício. Assim o estágio curricular supervisionado supõe uma relação pedagógica entre alguém que já é um profissional reconhecido em um ambiente institucional de trabalho e um aluno estagiário.

Ainda comenta que o estágio curricular supervisionado de ensino é um componente curricular obrigatório integrado à proposta pedagógica sob a supervisão de um profissional já habilitado. O estágio é um momento de formação profissional do formando e não é uma atividade facultativa, sendo uma das condições para a obtenção da respectiva licença, devendo ocorrer pelo exercício direto in loco, ou pela presença participativa em ambientes próprios de atividades daquela área profissional. O estágio, ainda segundo esse parecer, é necessário como momento de preparação próxima em uma unidade de ensino.

O parecer n. 28/2001 (Brasil, 2002) afirma que o estágio curricular supervisionado pretende oferecer ao futuro licenciado um conhecimento do real em situação de trabalho diretamente em unidades escolares dos sistemas de ensino. Com isso, entre outras coisas, o licenciando poderá acompanhar e compreender algumas atividades às quais não teria acesso como aluno, tais como planejamento de aulas e elaboração de projetos pedagógicos. Como ocorre a supervisão, o estagiário poderá exercer o papel de professor, integrando-se com os alunos e colegas professores, realizando uma rica troca de experiências e desenvolvendo as competências exigidas na sua futura prática profissional, especialmente quanto à regência.

Sendo uma atividade obrigatória, por sua característica já explicitada, ela deve ocorrer dentro de um tempo mais concentrado, mas não necessariamente em dias subsequentes. Com essa gama de exigências, o estágio curricular supervisionado da licenciatura não poderá ter uma duração inferior a 400 horas.

$\mathrm{O}$ documento especifica que

o tempo mínimo para todos os cursos superiores de graduação de formação de docentes para a atuação na educação básica para a execução das atividades científico-acadêmicas não poderá ficar abaixo de 2000 horas, sendo que, respeitadas as condições peculiares das instituições, estimula-se a inclusão de mais horas para estas atividades. Do total deste componente, 1800 horas serão dedicadas às atividades de ensino/aprendizagem e as demais 200 horas para outras formas 
de atividades de enriquecimento didático, curricular, científico e cultural. Estas 2000 horas de trabalho para execução de atividades científico-acadêmicas somadas às 400 horas da prática como componente curricular e às 400 horas de estágio curricular supervisionado são o campo da duração formativa em cujo terreno se plantará a organização do projeto pedagógico planejado para um total mínimo de 2800 horas. Este total não poderá ser realizado em tempo inferior a 3 anos de formação para todos os cursos de licenciatura, inclusive o curso normal superior. (Brasil, 2002)

Dessa forma, acabam-se as divergências em relação à carga horária dos cursos de formação de professores, bem como à importância do estágio supervisionado para o futuro docente.

\section{O ESTÁGIO SUPERVISIONADO SEGUNDO ALGUNS AUTORES}

A questão do estágio supervisionado não esteve em discussão apenas no aspecto legal, mas tem sido também foco de inúmeras pesquisas acadêmicas. Castro (2002 apud Fiorentini, 2008) e Rocha (2005 apud Fiorentini, 2008) afirmam que as práticas de ensino e os estágios supervisionados representam uma instância importante e fundamental à formação do professor, sendo marcada por intensa e significativa aprendizagem profissional.

Fiorentini (2008) afirma que pesquisas sobre o estágio indicam que, se queremos formar professores capazes de produzir e avançar nos conhecimentos curriculares e de transformar a prática/cultura escolar, então é preciso que eles adquiram uma formação inicial que lhes proporcione uma sólida base teórico-científica relativa ao seu campo de atuação, que deve ser desenvolvida apoiada na reflexão e na investigação sobre a prática. Isso requer um tempo relativamente longo de estudo e o desenvolvimento de uma prática de socialização profissional e iniciação à docência acompanhada de muita reflexão e investigação, tendo a orientação ou supervisão de formadores-pesquisadores qualificados.

Sobre o termo formação inicial, Diniz Pereira (2007, p. 86), citando Lortie (1975), faz a seguinte observação:

O termo "formação inicial", como se sabe, é criticado [...] pelo fato dessa formação iniciar-se muito antes da entrada em um curso ou programa que se desenvolve em uma instituição de ensino superior. Como se sabe, a profissão docente é suis generis, pois, mesmo antes da sua escolha ou de seu exercício, o futuro profissional já conviveu aproximadamente 12.000 horas com "o professor" durante o seu percurso escolar.

Toda essa experiência anterior tem um impacto na construção de modelos e concepções do que seja "o professor", "a aula", ou do que seja "ensinar". Segundo Wideen et al. (1998 apud Tardif, 2000), pesquisas produzidas em contextos educacionais bastante distintos do contexto educacional brasileiro mostram que os 
programas de "formação inicial", mais especificamente os estágios e as práticas de ensino, não são capazes de mudar concepções prévias dos alunos, futuros professores, sobre ensino-aprendizagem e muito menos as suas práticas pedagógicas.

Por sua vez, Diniz Pereira (2007) afirma que na realidade brasileira os estágios supervisionados e as práticas de ensino ocupam espaços pouco prestigiados nos currículos: em geral, aparecem bastante tardiamente nesse percurso, alimentando a ideia de que chegou a hora de aplicar os conhecimentos aprendidos (ou supostamente aprendidos) por meio das disciplinas de conteúdo específico e/ou pedagógicos.

Fiorentini et al. (2002), ao fazer uma revisão do tipo estado da arte de 112 pesquisas brasileiras realizadas até 2002 sobre formação de professores, verificaram que os principais problemas detectados pelas primeiras pesquisas (décadas de 1970 e 1980) ainda continuam presentes nos programas recentes de licenciatura em matemática (anos de 1990 e início dos anos 2000). Esses problemas são:

desarticulação entre teoria e prática, entre formação específica e pedagógica e entre formação e realidade escolar; menor prestígio da licenciatura em relação ao bacharelado; ausência de estudos histórico-filosóficos e epistemológicos; predominância de uma abordagem técnico-formal das disciplinas específicas; falta de formação teórico-prática em Educação Matemática dos formadores. (idem, 2002, p. 154)

Parece razoável subentender que o mesmo ocorre também com as demais licenciaturas. Pimenta e Lima (2004) afirmam que a dissociação entre a teoria e a prática resulta em um empobrecimento das práticas nas escolas, evidenciando a necessidade de explicitar por que o estágio é teoria e prática. As autoras comentam ainda que a profissão do educador é uma prática social, é uma forma de intervir na realidade social, pois a atividade docente é ao mesmo tempo prática e ação.

Candau e Lelis (1988 apud Fiorentini, 2008) comentam que nas práticas de formação tem ocorrido uma mudança de uma relação dicotômica dissociativa, com a teoria separada da prática, para uma relação dicotômica associativa entre teoria e prática. Na relação dicotômica associativa, segundo Fiorentini (2008), a teoria e a prática podem acontecer concomitantemente ao longo do curso, porém desenvolvidas como disciplinas justapostas - teóricas de um lado e práticas de outro -, isto é, sem articulação ou sem que seja estabelecida uma relação dialética entre elas, de modo que ambas possam se enriquecer mutuamente. Tardif (2000) comenta que a lógica disciplinar é altamente fragmentada e especializada, fazendo com que diversas disciplinas não tenham relação entre si, pois constituem unidades autônomas fechadas em si mesmas e de curta duração, portanto têm pouco impacto sobre os alunos.

Pimenta e Lima (2004) concluem que no estágio de cursos de formação de professores compete possibilitar que os futuros docentes compreendam a complexidade das práticas institucionais e das ações exercidas pelos profissionais como alternativa no preparo para a sua inserção profissional, mas isso só é conseguido se o estágio for uma preocupação, um eixo de todas as disciplinas do curso, que por sua vez devem contribuir para formar professores baseados na análise, na crítica e 
na proposição de novas maneiras de fazer educação, valorizando a prática profissional como momento de construção de conhecimento por meio do pensamento, da análise e da problematização dessa prática, atuando assim como um professor reflexivo ou professor pesquisador de sua prática.

Houssaye (2004) afirma que a formação inicial pode suscitar menos preocupações caso, entre outras coisas, a responsabilidade seja assumida de modo progressivo. $\mathrm{O}$ autor continua:

O sistema de estágios/formação metodológica (lições-padrão)/formação teórica (aulas ou debates) é inadaptado, pois faz dos estágios exercícios de "sobrevivência" que levam a um pragmatismo generalizado, e não a um profissionalismo com diversidade; quanto aos ciclos teóricos, na maioria das vezes desconexos de uma vivência, eles têm sobretudo um caráter de oásis. A sequência que leva o candidato ao domínio progressivo da animação é antes a seguinte: períodos de observação, períodos de atendimento mínimo (um aluno, um grupo, uma oficina), períodos de atendimento mais amplo, períodos de atendimento completo, tudo isso com uma supervisão constante e estruturada. (idem, p. 30).

O estágio prepara para um trabalho docente coletivo, pois o ensino, segundo Pimenta e Lima (2004), não é um assunto individual do professor, uma vez que a tarefa escolar é resultado das ações coletivas dos professores e das práticas institucionais. As autoras continuam afirmando que se pode "pensar o estágio como propostas que consideram a teoria e a prática presentes tanto na universidade quanto nas instituições-campo. O desafio é proceder ao intercâmbio, durante o processo formativo, entre o que se teoriza e o que se pratica em ambas" (idem, p. 127).

\section{O QUE OS ALUNOS PENSAM SOBRE O ESTÁGIO SUPERVISIONADO}

Para realizar esta pesquisa, colhemos por meio de questionários as opiniões de 72 estudantes ao longo de dois semestres letivos e, desse total de alunos, 30 eram do curso de licenciatura em matemática e 42 do curso de licenciatura em ciências biológicas. Os alunos de matemática estavam assim distribuídos: 20 eram alunos do $5^{\circ}$ módulo e cursavam a disciplina estágio supervisionado I, e 10 eram alunos concluintes ( $8^{\circ}$ módulo) que cursavam a disciplina de estágio supervisionado IV. Da mesma forma, os 42 alunos de ciências biológicas também estavam distribuídos nos seus cursos: 25 eram alunos do $5^{\circ}$ módulo e cursavam a disciplina de estágio supervisionado I, e 17 eram alunos do penúltimo módulo $\left(7^{\circ}\right)$ e cursavam a disciplina de estágio supervisionado III. Todos os estudantes investigados eram estudantes da Universidade Federal do Piauí (UFPI), campus Petrônio Portella, em Teresina. Todos os cursos oferecidos na UFPI são ofertados no sistema modular, com módulos de duração de um semestre. Vale salientar que desde o início do curso, já no primeiro módulo, os alunos cursam disciplinas de cunho pedagógico.

As ementas da disciplina estágio supervisionado são bastante parecidas entre si, com exceção da estágio supervisionado I, que tem uma carga horária de 
75 horas-aula e trata sobre o processo de formação e da trajetória da profissionalização docente e suas instâncias construtivas, além de trabalhar com oficinas de planejamento de ação docente, construção de materiais didáticos e utilização de novas tecnologias em educação. Já a estágio supervisionado II tem uma carga horária de 90 horas-aula e apresenta na sua ementa a elaboração do projeto de estágio e o estágio de observação. As ementas da estágio supervisionado III e IV abrangem o projeto de estágio e o estágio de regência, sendo a regência da estágio supervisionado III destinada às séries finais do ensino fundamental e a regência do estágio supervisionado IV destinada ao ensino médio. Esses apresentam uma carga horária de 120 horas-aula cada.

As perguntas do questionário foram todas abertas e as respostas categorizadas de maneira que agrupassem conteúdos semelhantes. A única questão de múltipla escolha era a que investigava onde o estudante havia cursado o ensino médio, na qual obtivemos o seguinte resultado:

Tabela 1 - Onde cursou o ensino médio?

\begin{tabular}{l|r|r|r}
\hline & \multicolumn{1}{|c|}{ Pública } & \multicolumn{1}{c|}{ Privada } & \multicolumn{1}{c}{ Filantrópica } \\
\hline ES I - Ciências Biológicas & $20(80 \%)$ & $6(24 \%)$ & - \\
\hline ES I - Matemática & $14(70 \%)$ & $5(25 \%)$ & $1(5 \%)$ \\
\hline ES III - Ciências Biológicas & $7(41,2 \%)$ & $10(58,8 \%)$ & $1(5,9 \%)$ \\
\hline ES IV - Matemática & $5(50 \%)$ & $5(50 \%)$ & - \\
\hline Total & $46(63,9 \%)$ & $26(36,1 \%)$ & $2(2,8 \%)$ \\
\hline
\end{tabular}

Fonte: Pesquisa direta.

Nota: ES: estágio supervisionado.

Elaboração do autor.

$\mathrm{Na}$ Tabela 1, percebemos que a maior porcentagem dos alunos era oriunda da rede pública de ensino, com $63,9 \%$, enquanto os alunos oriundos da rede privada eram $36,1 \%$ da amostra. Vemos também que há dois alunos $(2,8 \%)$ que cursaram o ensino médio em escolas filantrópicas. A porcentagem total de alunos foi maior que $100 \%$ em virtude de $2,8 \%$ dos alunos (dois alunos) terem estudado tanto na rede pública quanto na rede privada, sendo contabilizados em ambas as redes, justificando a porcentagem maior que $100 \%$ na estágio supervisionado I e III em ciências biológicas. Faz-se interessante observar que o perfil do aluno ingressante modificou, pois, na estágio supervisionado I em ciências biológicas e em matemática, a grande maioria veio de escola pública e isso não ocorreu na turma de estágio supervisionado III em ciências biológicas, em que a maioria era oriunda de escolas particulares, nem no estágio supervisionado IV em matemática, cuja turma era repartida equitativamente entre as redes pública e privada.

Creditamos essa mudança ao sistema de cotas para alunos da rede pública existente na UFPI em vigor desde 2006, quando oferecia 5\% das vagas para esses alunos passando em 2008 para $20 \%$ do total das vagas. Outro fator que pode ter influenciado para que houvesse esse aumento de alunos oriundos da rede pública de 
ensino é o fato de estar ocorrendo cursos pré-vestibulares gratuitos na própria UFPI e em diversas outras instituições, democratizando o acesso ao ensino de qualidade.

Após essa etapa, procuramos identificar qual(is) motivo(s) havia(m) levado cada um deles a cursar a licenciatura e obtivemos os resultados contidos na Tabela 2.

Tabela 2 - Por que cursar licenciatura?

\begin{tabular}{l|r|r|r|r|r|r|r}
\hline & \multicolumn{1}{|c|}{$\begin{array}{c}\text { Ex- } \\
\text { professor }\end{array}$} & $\begin{array}{c}\text { Gosta de } \\
\text { dar aula }\end{array}$ & $\begin{array}{c}\text { Trabalho } \\
\text { rápido }\end{array}$ & $\begin{array}{r}\text { Ensinol } \\
\text { Pesquisa }\end{array}$ & $\begin{array}{c}\text { Gosta do } \\
\text { conteúdo }\end{array}$ & Outras & Branco \\
\hline $\begin{array}{l}\text { ES I - Ciências } \\
\text { Biológicas }\end{array}$ & $4(16 \%)$ & $13(52 \%)$ & $2(8 \%)$ & $2(8 \%)$ & $3(12 \%)$ & $1(4 \%)$ & - \\
\hline $\begin{array}{l}\text { ES I - } \\
\text { Matemática }\end{array}$ & $3(15 \%)$ & $8(40 \%)$ & $3(15 \%)$ & - & $3(15 \%)$ & $2(10 \%)$ & $1(5 \%)$ \\
\hline $\begin{array}{l}\text { ES III - } \\
\text { Ciências } \\
\text { Biológicas }\end{array}$ & $2(11,8 \%)$ & $4(23,5 \%)$ & $2(11,8 \%)$ & $4(23,5 \%)$ & $3(17,6 \%)$ & $2(11,8 \%)$ & - \\
\hline $\begin{array}{l}\text { ES IV - } \\
\text { Matemática }\end{array}$ & - & $6(60 \%)$ & $2(20 \%)$ & $1(10 \%)$ & $1(10 \%)$ & - & - \\
\hline Total & $9(12,5 \%)$ & $31(43,1 \%)$ & $9(12,5 \%)$ & $7(9,7 \%)$ & $10(13,9 \%)$ & $5(6,9 \%)$ & $1(1,4 \%)$ \\
\hline
\end{tabular}

Fonte: Pesquisa direta.

Nota: ES: estágio supervisionado.

Elaboração do autor.

Cada resposta foi considerada em apenas uma categoria. As categorias foram:

1) Ex-professor: ingressou no curso porque teve bons professores da disciplina;

2) Gosta de dar aula: gosta de ensinar e/ou quer ser professor;

3) Trabalho rápido: a licenciatura proporciona uma grande facilidade para conseguir emprego rapidamente;

4) Ensino/Pesquisa: o curso de licenciatura é mais completo que o bacharelado, pois o profissional pode atuar na pesquisa e na docência;

5) Gosta do conteúdo: escolheu a licenciatura que cursa porque gosta de biologia ou de matemática;

6) Outras: categoria cujas respostas não se adequaram a nenhuma das respostas anteriores;

7) Branco: não responderam a essa questão.

$\mathrm{Na}$ categoria "ex-professor", apenas $12,5 \%$ responderam positivamente. A porcentagem das respostas foi semelhante entre os que cursavam a disciplina estágio supervisionado I e III em ciências biológicas e estágio supervisionado I em matemática. Nenhum aluno da estágio supervisionado IV em matemática citou essa categoria. A categoria "gosta de dar aula" foi a mais representativa, com 43,1\% dos investigados, diferentemente do que Lippe e Bastos (2008) verificaram em sua pesquisa, na qual apenas 2 alunos de um total de 53 investigados disseram se interessar pela docência. É importante observar que mais da metade dos alunos do 
estágio supervisionado I em ciências biológicas afirmou gostar de dar aula e depois o índice cai para cerca de um quarto para o total de respondentes que estão concluindo esse curso, o que pode sinalizar uma desmotivação no decorrer da formação, especialmente no contato com as escolas, que ocorre nos três últimos períodos do curso. Já em relação aos alunos de matemática ocorreu o inverso. Eles iniciaram gostando menos da docência (40\%) e terminaram o curso gostando mais de ensinar (60\%). Já 12,5\% dos respondentes foram inseridos na categoria “trabalho rápido”.

$\mathrm{Na}$ categoria "ensino/pesquisa", tivemos 9,7\% das respostas; e essas, em sua maioria, foram dadas pelos alunos concluintes, em especial pelos de ciências biológicas. Vale salientar que alguns desses alunos estavam ou estiveram envolvidos em iniciação científica e já mantiveram contato com a pesquisa acadêmica. Poucos alunos do $5^{\circ}$ módulo (ao menos entre os investigados) tiveram acesso às pesquisas dos seus departamentos. A categoria "gosta do conteúdo" também teve 13,9\% das respostas, sendo a segunda categoria mais citada pelos alunos. A maior porcentagem dessa categoria ocorreu com os alunos do estágio supervisionado III em ciências biológicas.

A categoria “outras" obteve 6,9\% das respostas. Essa categoria foi criada em virtude de respostas que destoaram das demais. Foram elas: influência da família; não ter passado no vestibular para outro curso; ser mais fácil passar no vestibular para cursos de licenciatura; poder atuar em gestão escolar. Um dos alunos cuja resposta está contabilizada nessa categoria afirmou não saber por que cursava a licenciatura escolhida e que ainda tinha dúvidas em relação à profissão. E a última categoria, "branco", teve apenas 1,4\% das respostas, apenas um indivíduo que nada respondeu.

Antes de chegarmos ao que os alunos esperavam do estágio, vamos observar a sua experiência docente, de forma que possamos ter mais subsídios para entender melhor as respostas. A experiência docente dos investigados encontra-se descrita na Tabela 3.

Tabela 3 - Experiência docente

\begin{tabular}{|l|c|c|r|r|r|r|r|r|r|}
\hline & Não & Prof & ES III & PIBID & Mon & Prog & Pré & Reforço & Igreja \\
\hline $\begin{array}{l}\text { ES I - } \\
\text { Ciências } \\
\text { Biológicas }\end{array}$ & $14(56 \%)$ & $3(12 \%)$ & - & - & - & $2(8 \%)$ & - & $4(16 \%)$ & $3(12 \%)$ \\
\hline $\begin{array}{l}\text { ES I - } \\
\text { Mate- } \\
\text { mática }\end{array}$ & $11(55 \%)$ & $1(5 \%)$ & - & $2(10 \%)$ & $2(10 \%)$ & $3(15 \%)$ & $1(5 \%)$ & $2(10 \%)$ & - \\
\hline $\begin{array}{l}\text { ES III - } \\
\text { Ciências } \\
\text { Biológicas }\end{array}$ & $1(5,9 \%)$ & $6(35,3 \%)$ & - & $2(11,8 \%)$ & $5(29,4 \%)$ & $3(17,6 \%)$ & $4(23,5 \%)$ & $4(23,5 \%)$ & - \\
\hline $\begin{array}{l}\text { ES IV - } \\
\text { Mate- } \\
\text { mática }\end{array}$ & - & $1(10 \%)$ & $10(100 \%)$ & $2(20 \%)$ & $2(20 \%)$ & - & $3(30 \%)$ & & - \\
\hline Total & $26(36,1 \%)$ & $11(15,3 \%)$ & $10(13,9 \%)$ & $6(8,3 \%)$ & $9(12,5 \%)$ & $8(11,1 \%)$ & $8(11,1 \%)$ & $10(13,9 \%)$ & $3(4,2 \%)$ \\
\hline
\end{tabular}

Fonte: Pesquisa direta.

Nota: ES: estágio supervisionado; Prof: professor; ES III: estágio supervisionado III; PIBID: Programa Institucional de Bolsa de Iniciação à Docência; Mon: monitor; Prog: programas; Pré: pré-vestibular.

Elaboração do autor. 
As respostas foram categorizadas nos seguintes grupos:

1) Não: nunca atuaram como docente;

2) Professor: atuavam ou atuaram como professores em escola regular;

3) Estágio Supervisionado III: tiveram experiência docente na disciplina estágio supervisionado III;

4) PIBID: atuaram como monitores do Programa Institucional de Bolsa de Iniciação à Docência;

5) Monitor: atuaram como docentes em monitorias na própria faculdade em que estuda;

6) Programas: atuaram como professores e/ou instrutores nos programas Mais Educação e/ou Escola Aberta;

7) Pré-vestibular: foram professores em cursos pré-vestibulares, basicamente aqueles oferecidos pela própria UFPI como projeto de extensão;

8) Reforço: deram aula de reforço escolar;

9) Igreja: atuaram como docentes em Escolas Bíblicas Dominicais ou como catequistas.

As respostas da Tabela 3 não totalizam 100\%, pois houve casos em que o mesmo estudante já havia atuado em escola e no PIBID ou no pré-vestibular e no estágio supervisionado, entre outros exemplos. Com base nas respostas, podemos verificar que apenas $15,3 \%$ dos respondentes têm experiência formal de sala de aula, como docente de pelo menos uma turma específica. A categoria mais expressiva foi a "não", com $36,1 \%$ dos estudantes investigados; contém mais da metade dos alunos da estágio supervisionado I em ciências biológicas ou em matemática (56\% e 55\%). Podemos observar também que a única turma em que todos os alunos já tiveram experiências como docentes foi a turma da estágio supervisionado IV em matemática, pois todos já haviam concluído a disciplina estágio supervisionado III.

É interessante constatar que os alunos que se encontravam no $5^{\circ}$ módulo (estágio supervisionado I), e ainda sem experiência docente, não haviam atuado em monitorias na própria universidade nem em pré-vestibulares, ou mesmo no PIBID. Vale salientar que a UFPI tem convênios com a Secretaria Estadual de Ensino do Piauí, desenvolvendo atividades do PIBID em escolas dessa rede, apresentando ainda dois projetos de cursos pré-vestibulares cujos docentes são estudantes vinculados às diversas licenciaturas da universidade. A seleção dos estudantes ocorre normalmente uma vez por ano, e o que pode justificar a ausência de alunos com experiência nesses programas de extensão é o fato de ser requisito estar, no mínimo, no $4^{\circ}$ módulo. Já em relação aos últimos módulos, tivemos 4 alunos atuando no PIBID, 7 em monitorias e 7 em pré-vestibulares, representando, respectivamente, $5,6 \%, 9,7 \%$ e $9,7 \%$ do total de alunos investigados.

Outro aspecto interessante é o fato de que 13,9\% dos alunos especificaram experiência docente por meio de aulas particulares. Essa é a experiência mais 
representativa em termos percentuais dos alunos que cursavam a estágio supervisionado I. Vale salientar que nenhum dos alunos da estágio supervisionado IV em matemática citou essa categoria, talvez por terem outras experiências que consideraram mais relevantes. No $5^{\circ}$ módulo de ciências biológicas, três alunos (12\%) relataram ter experiência docente em escolas bíblicas.

Com esses dados, fica claro que ao terminar o curso o estudante tem pouquíssima experiência de sala de aula e, por esse e por outros aspectos, torna-se ainda mais evidente a importância que o estágio supervisionado tem para esses alunos, pois poderão estabelecer contato com sua prática profissional e contar com a supervisão de um profissional mais experiente para auxiliá-los no que for necessário, dando-lhes muito mais tranquilidade para superar as dificuldades iniciais.

Após identificarmos um pouco melhor o perfil dos investigados, passemos ao que eles pensam em relação à disciplina de estágio supervisionado - enfatizando que a pesquisa foi feita na aula inaugural dessa disciplina com uma turma de matemática que realizaria regência no ensino médio e estava no último módulo do curso $\left(8^{\circ}\right)$, com uma turma de ciências biológicas que iria iniciar o período de regência no ensino fundamental e estava no penúltimo módulo (7º), e outras duas turmas (uma de matemática e outra de ciências biológicas) que estavam no $5^{\circ}$ módulo e iriam ter discussões sobre o estágio, não chegando a ir efetivamente a alguma instituição escolar de ensino. As respostas encontram-se sintetizadas na Tabela 4.

Tabela 4 - A disciplina acrescentará algo à sua formação?

\begin{tabular}{l|r|r|r|r|r|r}
\hline & $\begin{array}{c}\text { Teoria- } \\
\text { prática }\end{array}$ & $\begin{array}{c}\text { Visão } \\
\text { de ser } \\
\text { professor }\end{array}$ & $\begin{array}{c}\text { Experiência e } \\
\text { conhecimento }\end{array}$ & $\begin{array}{c}\text { Método e } \\
\text { técnica }\end{array}$ & Outras & Não \\
\hline $\begin{array}{l}\text { ES I - Ciências } \\
\text { Biológicas }\end{array}$ & $3(12 \%)$ & $4(16 \%)$ & $14(56 \%)$ & $5(20 \%)$ & - & - \\
\hline ES I - Matemática & $1(5 \%)$ & $7(35 \%)$ & $8(40 \%)$ & $3(15 \%)$ & $2(10 \%)$ & - \\
\hline $\begin{array}{l}\text { ES III - Ciências } \\
\text { Biológicas }\end{array}$ & $2(11,8 \%)$ & $2(11,8 \%)$ & $9(52,9 \%)$ & $3(17,6 \%)$ & $1(5,9 \%)$ & $1(5,9 \%)$ \\
\hline $\begin{array}{l}\text { ES IV - } \\
\text { Matemática }\end{array}$ & $1(10 \%)$ & $5(50 \%)$ & $4(40 \%)$ & - & - & - \\
\hline Total & $7(9,7 \%)$ & $18(25 \%)$ & $35(48,6 \%)$ & $11(15,3 \%)$ & $3(4,2 \%)$ & $1(1,4 \%)$ \\
\hline
\end{tabular}

Fonte: Pesquisa direta.

Nota: ES: estágio supervisionado.

Elaboração do autor.

Da mesma forma como na Tabela 3, o total aqui não dará 100\%, pois algumas das respostas transitaram entre duas ou mais categorias, sendo contadas em cada uma delas. A questão original era aberta e trazia o seguinte: "Você acha que essa disciplina acrescentará algo à sua formação? Por quê?” De acordo com as respostas, foram criadas as categorias listadas a seguir: 
1) Teoria-Prática: liga a teoria aprendida na universidade com a prática na sala de aula;

2) Visão de ser professor: faz o aluno ver o seu futuro como docente, bem como a realidade da escola;

3) Experiência e conhecimento: serve para adquirir experiência em sala de aula e novos conhecimentos;

4) Método e técnica: serve para aprender novos métodos e técnicas para aplicar em sala de aula;

5) Outras: respostas que não se enquadraram em nenhuma das categorias anteriores;

6) Não: não acrescenta nada.

É interessante observar a coerência entre as respostas dos alunos, pois a porcentagem de cada categoria foi basicamente idêntica para os dois grupos de alunos investigados.

$\mathrm{Na}$ categoria "teoria-prática", 9,7\% afirmaram ser essa disciplina uma ponte entre o que foi estudado durante a graduação e a realidade que os aguardava nas escolas. A resposta dada pelo Aluno 34 ilustra bem essa categoria: "Acredito que essa disciplina será de extrema importância na minha formação docente, pois ela deve proporcionar uma ligação entre o conteúdo aprendido na universidade com a prática docente". Esse tipo de resposta demonstra que o estágio para esses alunos tem grande importância por propiciar o que outras disciplinas do curso não fazem: unificar a teoria e a prática. Isso mostra a separação existente entre as disciplinas específicas e as pedagógicas.

Alarcão (1996) comenta que um dos maiores problemas dos cursos de formação inicial é a falta de articulação entre as disciplinas, bem como a falta de articulação entre o conteúdo ensinado e a prática efetiva, cabendo ao professor novato fazer a "ponte" entre teoria e prática. Muitos alunos ficam na expectativa de que essa seja a disciplina integradora; contudo, compactuamos com a visão de Pimenta e Lima (2004) de que a teoria e a prática devem existir em todas as disciplinas, ao longo da formação do professor. Brito (2006, p. 51) afirma que o conhecimento do professor se produz "tanto na própria experiência docente quanto nas trocas e intercâmbios vividos entre os professores [...], adquiridos na formação inicial e na própria experiência pessoal e profissional".

$\mathrm{Na}$ categoria "visão de ser professor", $25 \%$ afirmaram que essa disciplina servirá para que eles possam se ver como futuros docentes em sala de aula. Temos como exemplo dessa categoria a resposta dada pelo Aluno 7: "Sim. Me trará uma visão, mesmo que superficial, da minha vida como docente"; ou ainda a resposta dada pelo Aluno 61: "Com certeza, pois a realidade da educação muda a cada ano que passa [...] sendo assim, a disciplina de estágio poderá mostrar um pouco da verdadeira vida docente". Assim, para aqueles alunos que ainda têm dúvidas sobre a profissão proporcionada pelo curso, essa disciplina pode ajudar a encontrar uma resposta! Sobre isso, Libâneo (1994) comenta que a formação profissional do professor implica contínua interpenetração entre teoria e prática: a teoria vinculada aos problemas reais postos pela experiência prática e a ação prática orientada teoricamente. 
Em "experiência e conhecimento", temos como respostas aquelas que os alunos afirmaram que a disciplina servirá para acrescentar conhecimentos e experiências, auxiliando na prática futura em sala de aula. Quase metade dos respondentes foi contabilizada nessa categoria (48,6\%). Para ilustrar, verifiquemos as seguintes respostas: "Sim, pois através dessa disciplina iremos absorver novos conhecimentos, além de pegarmos experiência durante a regência" (Aluno 23); "Sim. Porque irá fazer com que eu adquira novos conhecimentos que possam ser aplicados em sala, com o intuito de facilitar a aprendizagem dos alunos" (Aluno 29).

$\mathrm{Na}$ categoria "método e técnica", tivemos 15,3\% do total de respostas. Ilustram bem essa categoria as seguintes respostas: "Sim. Espero, ao concluir a disciplina, ter domínio de práticas e técnicas que facilitem e/ou aperfeiçoem o ato docente" (Aluno 12); “Concerteza [sic] [...] a disciplina só aumentará o gosto pela docência e me dará métodos e técnicas para ensinar aos meus alunos” (Aluno 47); "Espero que sim. Por que [sic] o desejo de ser professor eu já tenho, mas preciso de mecanismos de operacionalização: como fazer? O que fazer?” (Aluno 68). Aqui temos respostas que exemplificam bem o importante papel no aprendizado e na vivência $d a$ e na docência que essa disciplina apresenta.

Além disso, essas respostas mostram que esses alunos consideram o estágio como um momento de aprendizado riquíssimo, talvez por ser a prática e ter um profissional para dar qualquer suporte que eventualmente necessitem. Diferente, porém, temos a resposta que foi inserida na categoria "não", quando o discente afirmou que: "Não. Disciplina acrescentada somente para preencher currículo" (Aluno 55). Isso foi um total de $1,4 \%$ das respostas. A categoria "outras" obteve $4,2 \%$ dos discentes e suas respostas não se adequaram às demais categorias, como a resposta do Aluno 18, que não compreendeu a pergunta e respondeu: "O estudo em biologia me proporcionou [...] conhecimentos [...] acerca do nosso meio ambiente", fugindo da questão e não podendo ser levada em conta.

Foi também solicitado ao alunos que apresentassem sugestões para que a disciplina de estágio fosse mais proveitosa para eles. As sugestões foram agrupadas em categorias que se encontram compiladas na Tabela 5.

Tabela 5 - Sugestões para melhorar a disciplina

\begin{tabular}{l|r|r|r|r|r|r}
\hline & Discussão & $\begin{array}{r}\text { Aulas } \\
\text { dinâmicas }\end{array}$ & Microaula & Realidade & Outras & Branco \\
\hline $\begin{array}{l}\text { ES I - Ciências } \\
\text { Biológicas }\end{array}$ & $18(72 \%)$ & $6(24 \%)$ & $4(16 \%)$ & $3(12 \%)$ & $1(4 \%)$ & $1(4 \%)$ \\
\hline ES I - Matemática & $8(40 \%)$ & $10(50 \%)$ & $4(20 \%)$ & - & - & $2(10 \%)$ \\
\hline $\begin{array}{l}\text { ES III - Ciências } \\
\text { Biológicas }\end{array}$ & $13(75,5 \%)$ & $5(29,4 \%)$ & - & $1(5,9 \%)$ & $4(23,5 \%)$ & $2(11,8 \%)$ \\
\hline ES IV - Matemática & $4(40 \%)$ & $1(10 \%)$ & - & $3(30 \%)$ & $2(20 \%)$ & $1(10 \%)$ \\
\hline Total & $43(59,7 \%)$ & $22(30,6 \%)$ & $8(11,1 \%)$ & $7(9,7 \%)$ & $7(9,7 \%)$ & $6(8,3 \%)$ \\
\hline
\end{tabular}

Fonte: Pesquisa direta.

Nota: ES: estágio supervisionado.

Elaboração do autor. 
Para essa tabela também foram criadas categorias e, como houve respostas que apresentavam mais de uma sugestão, o total de respostas será maior que 100\%. As categorias criadas foram as seguintes:

1) Discussão: as aulas devem ser discursivas, com grande interação entre o professor e os alunos;

2) Aulas dinâmicas: utilização de diferentes metodologias, tais como aulas dinâmicas, aulas com passeio, jogos educativos e outras atividades que estimulem o aprendizado;

3) Microaula: devem ocorrer microaulas, oficinas e/ou seminários;

4) Realidade: durante o estágio, deve ser enfatizada a realidade das escolas, priorizando o papel do professor e utilizando as experiências dos alunos que já atuam como professores;

5) Outras: respostas que não se adaptaram às outras categorias. Essas respostas englobaram diversas sugestões, como recomendar laboratórios equipados nas escolas, uso de vídeos educativos, aprofundamento nos Parâmetros Curriculares Nacionais (PCNs) ou ainda eliminar a disciplina;

6) Branco: categoria que contabilizou os alunos que nada sugeriram.

A categoria mais expressiva foi “discussão", com 59,7\% das respostas. É interessante verificar que os alunos de ciências biológicas sugeriram as discussões em mais de $70 \%$ das respostas, enquanto os alunos de matemática, $40 \%$, o que enfatiza a diferença de postura dos alunos, sendo os de ciências biológicas mais críticos e participativos que os de matemática.

A segunda categoria mais expressiva foi "aulas dinâmicas", com 30,6\% das respostas. As categorias "microaula", "realidade", "outras" e "branco" foram bem menos expressivas, com respectivamente, $11,1 \%, 9,7 \%, 9,7 \%$ e $8,3 \%$, merecendo destaque a categoria "microaula", pois todas as respostas que sugeriram essa categoria foram dadas por alunos que estavam no $5^{\circ}$ módulo (estágio supervisionado I), o que nos leva a pensar que os alunos que estão mais próximos de se formar não consideram os seminários, microaulas ou as oficinas como meios interessantes para torná-los profissionais mais aptos para a atuação docente.

Após verificar o que a legislação, os autores e os alunos compreendem sobre o estágio supervisionado, procuramos entender o que o professor colaborador (aquele que recebe o estagiário na escola) pensa sobre esse momento. Da mesma forma que ocorreu com os alunos, a coleta de dados foi realizada com questionários e as respostas obtidas encontram-se redigidas na seção a seguir. 


\section{O QUE OS PROFESSORES COLABORADORES PENSAM SOBRE O ESTÁGIO SUPERVISIONADO}

O professor participante da nossa pesquisa foi aquele professor que está lotado em escola da rede pública ${ }^{1}$ e que cede suas aulas para estagiários, para que esses possam ter um contato real com alunos nos diferentes níveis de ensino, supervisionando-os no papel de um profissional experiente. Com isso, o estagiário adquire mais experiência e segurança para a sua prática profissional futura e o professor colaborador poderá ter contato com novas metodologias. A troca de experiências é bastante salutar para ambos e essencial para a formação do aluno estagiário.

Tendo em vista a importância desse momento, especialmente para o licenciando, as questões foram aplicadas para professores colaboradores que receberam alunos de duas turmas de estágio supervisionado da UFPI. O total de professores investigados foi de 13 indivíduos, de cinco escolas diferentes. Das cinco escolas, uma era da rede municipal e quatro da rede estadual. Esses professores foram os responsáveis pelos estagiários das duas turmas supracitadas, que perfizeram um total de 27alunos; desses, 17 eram alunos de licenciatura em ciências biológicas que cursavam a disciplina estágio supervisionado III e realizavam o estágio de regência em escolas de nível fundamental, e 10 eram alunos de licenciatura em matemática que cursavam a disciplina de estágio supervisionado IV e realizavam o estágio de regência em escolas de nível médio,tal como determinavam os cursos e as ementas das disciplinas. Esse pequeno número de alunos ocorreu em virtude da grande evasão que ocorreu nas licenciaturas das ciências exatas e da natureza (Diogo; Gobara, 2007; Gatti; Barreto, 2009; Rodrigues; Teixeira, 2009).

Como vimos anteriormente, segundo as ementas, no estágio supervisionado III o licenciando da UFPI deve realizar o projeto de estágio e ministrar a regência em escolas do ensino fundamental II na disciplina ciências (no caso do aluno de ciências biológicas, física e química), visto que nesse nível de ensino normalmente os assuntos relativos à biologia, química e física são trabalhados em ciências, que, segundo os PCNs (Brasil, 2001), compreendem ainda astronomia e geociências. Já no estágio supervisionado IV, o licenciando da UFPI deve realizar o projeto de estágio e ministrar a regência em escolas do ensino médio.

Durante o estágio supervisionado, o estagiário deve assumir uma turma, fazendo o planejamento, ministrando aula, elaborando e aplicando provas, bem como participando das diversas atividades da escola (reunião de professores, Feira

1 Para que ocorra o estágio supervisionado de ensino de alunos da UFPI em determinada instituição, esta deve ter convênio assinado com a universidade citada. $\mathrm{Na}$ prática, observamos que esse convênio existe para os estágios supervisionados de ensino apenas com escolas da rede estadual de ensino do Piauí, municipal de ensino de Teresina. As escolas filantrópicas de Teresina são em sua maioria vinculadas a escolas privadas, e as escolas privadas não permitem o estágio curricular de ensino em suas dependências e, portanto, não têm convênio assinado com esse fim. 
de Ciências, dia temáticos - Dia do Meio Ambiente, festas cívicas, entre outros). O estágio deve ocorrer de forma semelhante à que se pretende na prática do futuro professor.

As escolas nas quais os professores atuavam, bem como as disciplinas que eles ministravam, estão discriminadas na Tabela 6:

Tabela 6 - Escolas e disciplinas dos professores colaboradores

\begin{tabular}{|l|r|r|r|r|r|r|}
\hline \multirow{2}{*}{\multicolumn{1}{c|}{ Disciplina }} & \multicolumn{6}{|c|}{ Número de Professores } \\
\cline { 2 - 8 } & Escola A & Escola B & Escola C & Escola D & Escola E & \multicolumn{1}{c|}{ Total } \\
\hline Ciências Biológicas & 1 & 2 & - & - & 1 & 4 \\
\hline Matemática & 2 & - & 1 & 6 & - & 9 \\
\hline Total & 3 & 2 & 1 & 6 & 1 & 13 \\
\hline
\end{tabular}

Fonte: Pesquisa direta.

Elaboração do autor.

Podemos observar que, embora o número de alunos de ciências biológicas fosse maior, temos menos professores colaboradores que ministravam aulas de ciências que docentes que ministravam aulas de matemática. Isso pode ser explicado pelo simples fato de que a carga horária de matemática para o ensino fundamental II, nas escolas em que os professores investigados trabalhavam, era de seis aulas por semana, enquanto a disciplina ciências apresentava apenas duas aulas semanais. Com isso, para que o docente da disciplina de ciências completasse a sua carga horária, ele deveria atuar em mais turmas que o professor de matemática, tendo, portanto, mais turmas, o que implica maior possibilidade de aceitar estagiários. As escolas foram escolhidas levando-se em conta o deslocamento dos alunos (utilização de apenas um ônibus) e a disponibilidade da equipe gestora e dos professores em absorver os estagiários.

Quanto ao sexo dos professores colaboradores, observamos o seguinte:

Tabela 7 - Sexo dos professores colaboradores

\begin{tabular}{l|r|r|r}
\hline \multirow{2}{*}{ Sexo } & \multicolumn{3}{|c}{ Disciplina } \\
\cline { 2 - 4 } & Ciências & Matemática & \multicolumn{1}{c}{ Total } \\
\hline Masculino & 3 & 9 & $12(92,3 \%)$ \\
\hline Feminino & 1 & - & $1(7,7 \%)$ \\
\hline
\end{tabular}

Fonte: Pesquisa direta.

Elaboração do autor.

Podemos observar na Tabela 7 que os professores colaboradores da amostra eram, em sua maioria (92,3\%), do sexo masculino. Um detalhe interessante é o fato de que na amostra nenhuma mulher lecionava matemática. A baixa presença feminina na área da matemática também foi enfatizada em outras pesquisas (Cavalari, 2010; Fernandes, 2006).

Quanto ao tempo de serviço como professor, na Tabela 8 observamos o seguinte resultado: 
Tabela 8 - Tempo de serviço dos professores colaboradores

\begin{tabular}{l|c|c|c|c|c|c}
\hline Tempo de ensino (anos) & $0 \cdot 2$ & $3 \cdot 5$ & $6 \cdot 10$ & $11 \cdot 15$ & $16 \cdot 20$ & + de 21 \\
\hline Número de professores & $1(7,7 \%)$ & $1(7,7 \%)$ & $5(38,4 \%)$ & $2(15,4 \%)$ & $2(15,4 \%)$ & $2(15,4 \%)$ \\
\hline
\end{tabular}

Fonte: Pesquisa direta.

Elaboração do autor.

De acordo com a Tabela 8, podemos perceber que os professores colaboradores da amostra tinham, na sua maioria, até dez anos de serviço. Esse fato nos remete a duas possibilidades: está havendo uma renovação no atual quadro docente, ou os professores mais novos estão mais abertos aos estagiários. Não temos como determinar qual dessas possibilidades é a real e assim, como esse não é o foco desta pesquisa, deixaremos essa investigação para pesquisas futuras.

Tendo em vista que os alunos estagiários teriam contato direto com os professores colaboradores, investigamos quais os materiais utilizados por esses professores para preparar as suas aulas. A Tabela 9 sintetiza os resultados.

Tabela 9 - Material utilizado pelos professores colaboradores

\begin{tabular}{l|c|c|c|c|c|c|c|c}
\hline & $\begin{array}{c}\text { Livro } \\
\text { Didático }\end{array}$ & Música & Internet & Revistas & Livros & Jogos & Filmes & Outros \\
\hline Total & $13(100 \%)$ & $1(7,7 \%)$ & $2(15,4 \%)$ & $4(30,8 \%)$ & $7(53,8 \%)$ & - & $1(7,7 \%)$ & $3(23,1 \%)$ \\
\hline
\end{tabular}

Fonte: Pesquisa direta.

Elaboração do autor.

Podemos observar que a soma dos valores das colunas é um valor maior que $100 \%$. Isso se deve ao fato de que alguns professores utilizavam mais de um material na preparação de suas aulas. Como já esperado, o principal material usado por esses professores para o planejamento de suas aulas era o livro didático, com $100 \%$ das respostas, em conformidade com o Instituto Brasileiro de Geografia e Estatística (IBGE) (1982) e com Rodrigues (2010). Em 30,8\% dos investigados, o livro didático era o único material utilizado. Considerando que os alunos estagiários entraram em contato direto com esses professores, podemos supor que futuramente eles, enquanto professores, poderão ser propagadores dessa realidade e ficar presos apenas ao livro didático, deixando de utilizar outros materiais que poderão facilitar a compreensão dos alunos sobre as diversas temáticas abordadas em sala de aula.

Pouco mais da metade dos investigados $(53,8 \%)$ utilizava outros livros didáticos além do adotado na disciplina. Esse fato é positivo, pois assim o professor terá acesso a novas formas de abordar os conteúdos, bem como a uma visão mais completa sobre eles, visto que alguns livros tratam de determinados conteúdos com mais profundidade que outros, especialmente se o livro adotado é algum volume único (que no ensino médio engloba resumidamente os conteúdos das três séries) e o outro livro consultado é de uma série específica $\left(1^{\circ}, 2^{\circ}\right.$ ou $3^{\circ}$ ano).

Outro detalhe interessante observado na pesquisa foi que apenas os professores de ciências utilizavam música ou filmes, e apenas professores de matemática 
utilizavam revistas - a única citada foi a Revista do Professor de Matemática, que é disponibilizada pela escola. Embora fosse disponível a todos os professores investigados, apenas $15,4 \%$ desses utilizavam a internet para planejar e executar as suas aulas. Um fato que chamou a atenção foi que nenhum dos professores investigados utilizava jogos didáticos, visto que três deles atuavam em uma escola na qual funcionava o PIBID em parceria com a UFPI, e outros dois docentes atuavam em uma escola em que já havia funcionado o mesmo programa. Uma das ações diversificadas mais comuns do PIBID, pelo menos na realidade de Teresina (PI), é a utilização de jogos didáticos como estratégia de ensino. Essa estratégia, a nosso ver, parece interessante ao aluno da escola e ao bolsista da universidade, mas não deve parecer ao docente da escola. Os que citaram "outros" relataram utilizar o laboratório de matemática ou listas de exercício.

Após todos esses dados, questionamos qual era a opinião do professor colaborador sobre o estágio supervisionado. Como era uma questão aberta, para facilitar o entendimento, categorizamos as respostas semelhantes, tal como mostra a Tabela 10.

Tabela 10 - Para que serve o estágio supervisionado?

\begin{tabular}{r|r|r|r}
\hline Realidade & Segurança & Experiência & Outros \\
\hline $7(53,8 \%)$ & $1(7,7 \%)$ & $7(53,8 \%)$ & $1(7,7 \%)$ \\
\hline
\end{tabular}

Fonte: Pesquisa direta.

Elaboração do autor.

Podemos observar que o somatório das respostas é maior que 100\%. Isso se deve ao fato de que algumas respostas foram consideradas em mais de uma categoria. As categorias foram:

1) Realidade: mostra a realidade das escolas e salas de aula;

2) Segurança: fornece meios para que o estagiário adquira maior segurança para a atuação em sala de aula;

3) Experiência: por meio do estágio, o estagiário adquire mais experiência;

4) Outros: a carga horária do estágio era resumida e deveria ser ampliada.

Com base nos dados expostos na Tabela 10, podemos observar que os professores colaboradores consideravam, em sua maioria, que o estágio supervisionado servia para o aluno estagiário conhecer a realidade da escola, com 53,8\% das respostas, e para adquirir experiência, com os mesmos 53,8\%. Apenas um indivíduo $(7,7 \%)$ respondeu que o estágio supervisionado servia para que o aluno estagiário adquirisse segurança para a prática docente. Outros $7,7 \%$ responderam que a carga horária do estágio era resumida, sendo, pois, necessário que houvesse a sua ampliação.

Também foi questionado sobre a supervisão do estágio pela universidade, sob a forma de questão aberta. Para expor as respostas, criamos categorias que estão discriminadas na Tabela 11. 
Tabela 11 - Como deve ser realizada a supervisão do estágio pela universidade?

\begin{tabular}{r|r|r|r|r}
\hline Professor & Relatório & $\begin{array}{c}\text { Proximidade } \\
\text { com o aluno }\end{array}$ & $\begin{array}{c}\text { Proximidade } \\
\text { com o professor }\end{array}$ & \multicolumn{1}{c}{ Subsídios } \\
\hline $5(38,4 \%)$ & $1(7,7 \%)$ & $4(30,8 \%)$ & $4(30,8 \%)$ & $1(7,7 \%)$ \\
\hline
\end{tabular}

Fonte: Pesquisa direta.

Elaboração do autor.

Da mesma forma que na Tabela 10, a soma das respostas da Tabela 11 é maior que $100 \%$ por haver respostas que abrangiam mais de uma categoria. As categorias criadas foram:

1) Professor: a supervisão do estágio deve ser feita pelo professor da disciplina de estágio supervisionado;

2) Relatório: a supervisão deve ser realizada com base no que o aluno estagiário escrever no seu relatório de estágio;

3) Proximidade com o aluno: a supervisão pela universidade deve ser realizada mais próxima aos alunos;

4) Proximidade com o professor: a supervisão pela universidade deve ocorrer com uma maior proximidade com o professor colaborador;

5) Subsídios: a universidade (ou a disciplina de estágio supervisionado) deve fornecer subsídios para que o aluno compreenda o que é o estágio e como esse deve ocorrer.

Com base nas respostas contidas na Tabela 11, podemos ver que a categoria mais expressiva nas respostas dos professores colaboradores foi que a supervisão deveria ser realizada pelo professor da disciplina, com $38,4 \%$. Se levarmos em conta que esse professor é a pessoa da universidade que está mais próxima dos alunos estagiários e dos professores colaboradores na escola, esse número sobe para 100\%, ou seja, para a totalidade das respostas.

As categorias "proximidade com o aluno" e "proximidade com o professor" indicaram que os professores colaboradores estavam insatisfeitos com a supervisão dos estágios pela universidade, demonstrando que a instituição estava distante dos alunos e dos professores colaboradores durante a prática do estágio. Tendo em vista que, por resolução, o professor da universidade deve ter no máximo 15 alunos matriculados nas disciplinas de estágio (UFPI, 1995) com o objetivo de realizar uma supervisão mais efetiva. Contudo, isso não é o que ocorre ${ }^{2}$ (ao menos, essa é a realidade na UFPI, que apresenta carência de profissionais e excesso de alunos;

$2 \mathrm{Na}$ época da realização desta pesquisa, o autor estava lecionando para uma turma de estágio de regência com 22 alunos matriculados. Esse fato acontece corriqueiramente, havendo casos em que o docente leciona para turma de estágio supervisionado com mais de trinta alunos. 
porém, pode ser a realidade em outras universidades). Então, essa supervisão mais próxima ainda é uma possibilidade distante da realidade.

Ainda houve respostas afirmando que a supervisão deveria ocorrer com base nos relatórios de estágio redigidos pelos alunos (a resposta que continha essa categoria também continha a categoria "professor") e que a universidade deveria dar subsídios para o aluno compreender o que é o estágio e como ele deveria ocorrer, sendo uma resposta para cada categoria.

Tabela 12 - Como deve ser realizada a supervisão do estágio pela escola?

\begin{tabular}{r|r|c|r|r}
\hline Cotidiano & Professor & \multicolumn{1}{c|}{$\begin{array}{c}\text { Professor/ } \\
\text { gestão }\end{array}$} & \multicolumn{1}{c}{ Outros } & \multicolumn{1}{c}{$\begin{array}{c}\text { Não } \\
\text { especificado }\end{array}$} \\
\hline $1(7,7 \%)$ & $6(46,2 \%)$ & $3(23,1 \%)$ & $2(15,4 \%)$ & $1(7,7 \%)$ \\
\hline
\end{tabular}

Fonte: Pesquisa direta.

Elaboração do autor.

$\mathrm{Na}$ Tabela 12 estão as respostas acerca do que os professores pensam sobre a supervisão do estágio, sendo a soma do total igual a 100\%. Como as respostas eram abertas, criamos categorias para agrupá-las e facilitar o entendimento. Vejamos as seguintes categorias:

1) Cotidiano: a escola deve mostrar o que acontece no dia a dia do professor, explicitando como é o seu trabalho, domínio de turma, integração com os alunos etc.;

2) Professor: o professor da disciplina que o estagiário lecionará deve fazer a supervisão, discutindo, planejando, observando e intervindo;

3) Professor/gestão: a supervisão deve ser realizada pelo professor da disciplina em conjunto com a gestão da escola (coordenação, direção etc);

4) Outros: respostas que não se adequaram às outras categorias, como oferecer subsídios para o aluno desenvolver habilidades ou com o professor sendo avaliado pelo aluno;

5) Não epecificado: o pesquisado não respondeu a essa questão.

Com base nos dados da Tabela 12, obervamos que a categoria mais expressiva foi "professor", com $46,2 \%$ das respostas. Isso mostra que o procedimento habitual de supervisão do estágio pela escola, segundo os docentes aqui pesquisados, deve continuar da maneira que vem ocorrendo. Em algumas respostas, constatamos que os professores colaboradores afirmaram que nessa supervisão o professor colaborador deveria discutir a matéria com os estagiários e planejar com eles, intervindo quando necessário.

A outra categoria mais citada foi "professor/gestão", com 23,1\% das respostas. Essa categoria coloca a supervisão do estágio na escola sob a responsabilidade do professor colaborador, mas não mais sozinho, agora em conjunto com o corpo gestor da instituição. Outras respostas foram dadas (enfatizar o dia a dia do professor na 
escola, oferecer subsídios para o estagiário desenvolver as suas habilidades e o professor colaborador ser avaliado pelos alunos), mas não se adequavam necessariamente ao propósito da questão. Houve ainda um professor $(7,7 \%)$ que não especificou a sua resposta, deixando-a em branco.

Procuramos também compreender a opinião dos professores colaboradores sobre o local em que deveria ocorrer o estágio supervisionado. As respostas seguem na Tabela 13.

Tabela 13 - Em quais escolas deve ocorrer o estágio supervisionado?

\begin{tabular}{c|r|r|r|r|r|r}
\hline $\begin{array}{c}\text { Escola de } \\
\text { aplicação }\end{array}$ & Referência & Pública & Privada & Mesma & Variar & Outros \\
\hline $2(15,4 \%)$ & $2(15,4 \%)$ & $2(15,4 \%)$ & $3(23,1 \%)$ & - & $7(53,8 \%)$ & $3(23,1 \%)$ \\
\hline
\end{tabular}

Fonte: Pesquisa direta.

Elaboração do autor.

Diferentemente dos últimos dados, essa não era uma questão aberta, havendo opções de múltipla escolha. Os resultados obtidos nas diferentes categorias somam mais de $100 \%$ em virtude de alguns sujeitos terem assinalado mais de uma opção em suas respostas. As categorias criadas foram:

1) Escola de aplicação: escola de aplicação vinculada à universidade;

2) Referência: escola de referência da rede pública;

3) Pública: escola da rede pública que não seja de referência;

4) Privada: escola privada;

5) Mesma: o estágio deve ocorrer sempre nas mesmas escolas;

6) Variar: o estágio deve ocorrer em escolas variadas;

7) Outros: o estágio deve ocorrer em escolas escolhidas de acordo com a conveniência; ou o estágio deve ocorrer em escolas que tenham o corpo gestor comprometido com a qualidade da educação.

De acordo com os dados contidos na Tabela 13, podemos observar que a maioria dos docentes $(53,8 \%)$ acreditava que o estágio supervisionado deveria ocorrer em diferentes escolas. A rede pública foi a mais citada pelos docentes, 46,2\% (escola de aplicação + referência + pública) contra 23,1\% daqueles que afirmaram que o estágio deveria ocorrer em escolas da rede privada. Nenhum dos investigados afirmou que o estágio deveria ocorrer sempre na mesma escola. Houve também as respostas que não se enquadraram diretamente nas categorias preestabelecidas, com $23,1 \%$. Essas respostas, de forma geral, afirmavam que o estágio deveria ocorrer em escolas de fácil acesso para os estagiários e professores, bem como ter o corpo gestor comprometido com a qualidade da educação. 


\section{NOTAS CONCLUSIVAS}

O estágio supervisionado é visto como tendo influência negativa para a opção pela carreira do magistério (Lippe; Bastos, 2008), pois mostra uma situação desestimulante encontrada principalmente nas escolas públicas. Martins (2009) ressalta que a precariedade da infraestrutura física das escolas públicas foi apontada nos relatórios de estágio de licenciandos como associadas a dificuldades por eles enfrentadas. Mendes (2006, p. 196) explicita que

Atualmente têm-se tentado mudar a feição da Prática de Ensino e do Estágio Supervisionado, pelo menos teoricamente, conferindo às disciplinas uma conotação mais reflexiva e crítica, buscando encontrar caminhos que favoreçam um melhor desempenho dos alunos estagiários no enfrentamento dos desafios do ensino público, principalmente o fracasso escolar, que gera o desestímulo do alunado, compromete a ação docente e, de certa forma, desarticula o processo educacional.

Pudemos verificar pelas respostas dos alunos que - mesmo estando em momentos distintos dos cursos (uma parte dos alunos investigados estava na metade do seu curso e a outra o estava concluindo), sendo de origens diferentes (alunos do $5^{\circ}$ módulo eram em sua maioria oriundos da escola pública, e os do $7^{\circ}$ e $8^{\circ}$ módulos eram da escola privada) e tendo experiências docentes bem distintas (mais da metade dos alunos do $5^{\circ}$ período não teve experiência docente, contra a grande maioria dos concluintes, que já tinha se envolvido com cursos pré-vestibulares, com o PIBID, monitorias etc.) - houve um consenso em relação à função do estágio, com quase metade dos alunos investigados (48,6\%), considerando essa disciplina capaz de acrescentar experiência e conhecimento de sala de aula, e com 59,7\% dos alunos sugerindo que a melhor maneira de prepará-los para a futura prática docente é por meio de discussões e debates, mostrando uma postura crítica, ativa e reflexiva.

Também observamos que, ao menos nesta pesquisa, a maior parte dos professores colaboradores investigados $(53,8 \%)$ tinha até dez anos de docência, que continuavam presos ao livro didático para efetuar o planejamento do ensino, mas que outros meios também estavam sendo utilizados, em menor escala, como outros livros, internet, revistas etc. Observamos também que 53,8\% dos professores investigados acreditavam que o estágio servia para mostrar a realidade aos alunos estagiários, bem como para que esses pudessem adquirir experiência de sala de aula.

Os professores colaboradores comentaram ainda, em sua maioria, que a supervisão pela universidade deveria ser realizada pelo professor da disciplina de estágio supervisionado, porém de forma mais próxima aos alunos estagiários e aos professores colaboradores, e a supervisão pela escola deveria ser realizada pelo professor colaborador, tal como vem acontecendo há tempos. Por fim, em relação ao local que deveria ocorrer o estágio, a maior parte dos professores colaboradores afirmou que esse momento deveria variar, não ocorrer sempre nas mesmas escolas, mas estas deveriam ser vinculadas à rede pública de educação. 
Neste artigo, observamos quanto o estágio é importante para a formação dos futuros professores. Enfatizamos o aumento da carga horária para o estágio e a defesa de autores para que sobre essa disciplina não recaia toda a responsabilidade de ofertar a "prática" aos alunos, visto que todas as disciplinas são ao mesmo tempo teóricas e práticas. Vimos que a maioria dos alunos investigados está em consonância com o que os autores estão redigindo: o estágio é um momento de reflexão, de observar-se enquanto professor e por esse momento pode-se repensar as práticas de modo que se melhore a cada dia enquanto profissional. Também verificamos que os professores colaboradores estão em conformidade com o que a academia tem realizado.

Lima (2006, p. 35) afirma que "o mundo atual requer um novo tipo de profissional, cujos saberes sejam polivalentes e, sobretudo, amplos e sólidos, para corresponder às peculiaridades e ao caráter multifacetado da prática pedagógica”. É importante que os diversos sujeitos envolvidos no processo de estágio (professor da disciplina, professor colaborador e aluno estagiário), bem como as instituições (universidade e escola), estejam em sintonia, para que o estágio seja realmente uma parte interessante e necessária para a formação do futuro docente, tornando-o mais apto para a realização do ofício da docência. Esta pesquisa ainda se encontra em andamento, pois tivemos o que os alunos pensam acerca do estágio antes de realizá-1o. Ao terminarem o estágio, os estudantes poderão fazer uma avaliação das experiências vividas durante esse período e poderão formular um melhor juízo de valor sobre a disciplina cursada.

Esse é o nosso desafio como docente, observar cada aula como uma nova possibilidade de adquirir conhecimentos e experiências, as quais nos tornarão melhores e, como dizia Freire (1996), conscientes do nosso inacabamento, visto que estamos constantemente em formação.

\section{REFERÊNCIAS}

Alarcão, Isabel. Formação reflexiva de professores: estratégias de supervisão. Porto: Porto Editora, 1996.

Brasil. Lei n. 9.394, de 20 de dezembro de 1996. Estabelece as Diretrizes e Bases da Educação Nacional. Diário Oficial da União, Brasília, DF, 23 dez. 1996. Disponível em: <http://www.planalto.gov.br/ccivil/LEIS/ L9394.htm>. Acesso em: 5 ago. 2008.

- Parâmetros Curriculares Nacionais: ciências naturais. 3. ed. Brasília, DF: Ministério da Educação/Secretaria de Educação Fundamental, 2001.

. Parecer CNE/CP n. 28/2001, de 2 de outubro de 2001. Dá nova redação ao parecer n. CNE/CP 21/2001, que estabelece a duração e a carga horária dos cursos de formação de professores da educação básica, em nível superior, curso de licenciatura, de graduação plena. Diário Oficial da União, Brasília, DF, 18 jan. 2002. Disponível em: <http://portal.mec.gov.br/cne/arquivos/pdf/028.pdf>. Acesso em: 15 ago. 2010. 
Lei n. 11.738, de 16 de julho de 2008. Regulamenta a alínea "e" do inciso III do caput do artigo 60 do Ato das Disposições Constitucionais Transitórias, para instituir o piso salarial profissional nacional para os profissionais do magistério público da educação básica. Diário Oficial da União, Brasília, DF, 17 jul. 2008. [2008a]. Disponível em: <http://planalto.gov.br/ccivil_03/_Ato2007-2010/2008/Lei/_L11738.htm>. Acesso em: 26 out. 2010.

Lei n. 11.788, de 25 de setembro de 2008. Dispõe sobre o estágio de estudantes [...] e dá outras providências. Diário Oficial da União, Brasília, DF, 26 set. 2008. [2008b]. Disponível em: <http://www.planalto.gov.br/ccivil_03/_ato2007-2010/2008/lei/111788. htm>. Acesso em: 22 out. 2010.

Brito, Antônia Edna. Formar professores: rediscutindo o trabalho e os saberes docentes. In: Mendes Sobrinho, José Augusto de Carvalho; Carvalho, Marlene Araújo de (Orgs.). Formação de professores e práticas docentes: olhares contemporâneos. Belo Horizonte: Autêntica, 2006.

Cavalari, Mariana Feiteiro. História, mulheres e educação matemática. In: Encontro Nacional de Educação Matemática, 10., 2010, Salvador. Anais eletrônicos... Salvador, UFBA, 2010. Disponível em: <http://www.moodle.ufba.br/file.php/11468/ hist_ria_no_ensino_de_matematica/T6_CC1355.pdf >. Acesso em: 13 jan 2011.

Diniz Pereira, Júlio Emílio. Formação de professores, trabalho docente e suas repercussões na escola e na sala de aula. Educação Ė Linguagem, São Paulo: Universidade Metodista de São Paulo, ano 10, n. 15, p. 82-98, jan./jun. 2007.

Diogo, Rodrigo Claudino; Gobara, Shirley Takeco. Sociedade, educação e ensino de física no Brasil: do Brasil Colônia a Era Vargas. In: Simpósio Nacional de Ensino DE Física, 17., 2007, São Luís. Anais eletrônicos... São Luís, SBF, 2007. Disponível em: <http://www.sbf1.sbfísica.org.br/eventos/snef/xvii/programa>. Acesso em: 20 maio 2008.

Fernandes, Maria da Conceição Vieira. A inserção e vivência da mulher na docência de matemática: uma questão de gênero. Dissertação (Mestrado em Educação) - Centro de Educação, Universidade Federal da Paraíba, João Pessoa, 2006.

Fiorentini, Dario. A pesquisa e as práticas de formação de professores de matemática em face das políticas públicas no Brasil. Bolema, Rio Claro: UNESP, ano 21, n. 29, 2008, p. 43-70.

Fiorentini, Dario; Nacarato, Adair Mendes; Ferreira, Ana Cristina; Lopes, Celi Espasandin; Freitas, Maria Teresa Menezes de; Miskulin, Rosana Giaretta Sguerra. Formação de professores que ensinam matemática: um balanço de 25 anos da pesquisa brasileira. Educaşão em Revista, Belo Horizonte: UFMG, n. 36, p.137-160, 2002. Dossiê "Educação Matemática".

Freire, Paulo. Pedagogia da autonomia: saberes necessários à prática educativa. São Paulo: Paz e Terra, 1996.

Instituto Brasileiro de Geografia e Estatística-IBGE. Pesquisa Nacional por Amostra de Domicílio (PNAD). Rio de Janeiro, 1982. 
Gatti, Bernadete Angelina; Barretto, Elba Siqueira de Sá. Professores no Brasil: impasses e desafios. Brasília: UNESCO, 2009. Disponível em: <http://unesdoc.unesco. org/images/0018/001846/184682POR.pdf>. Acesso em: 11 out. 2009.

Houssaye, Jean. Pedagogia: justiça para uma causa perdida. In: Houssaye, Jean; Soëtard, Michel; Hameline, Daniel; Fabre, Michel. Manifesto a favor dos pedagogos. Tradução de Vanise Dresch. Porto Alegre: Artmed, 2004. p. 9-45.

Libâneo, José Carlos. Didática. São Paulo: Cortez, 1994.

Lima, Maria da Glória Soares Barbosa. Sujeitos e saberes, movimento de autorreforma da escola. In: Mendes Sobrinho, José Augusto de Carvalho; Carvalho, Marlene Araújo de (Orgs.). Formação de professores e práticas docentes: olhares contemporâneos. Belo Horizonte: Autêntica, 2006. p. 31-39.

Lıppe, Eliza Márcia Oliveira; BAstos, Fernando. Formação inicial de professores em biologia: fatores que influenciam o interesse pela carreira do magistério. In: BAstos, Fernando; NARDi, Roberto. Formação de professores e práticas pedagógicas no ensino de ciências: contribuições da pesquisa na área. São Paulo: Escritura Editora, 2008.

Martins, André Ferrer Pinto. Estágio supervisionado em física: o pulso ainda pulsa... Revista Brasileira de Ensino de Física, São Paulo: Sociedade Brasileira de Física, v. 31, n. 3, p. 3.402-1-3.402-7, 2009.

Mendes, Bárbara Maria Macêdo. Novo olhar sobre a prática de ensino e o estágio curricular supervisionado de ensino. In: Mendes Sobrinho, José Augusto de Carvalho; Carvalho, Marlene Araújo de (Orgs.). Formação de professores e práticas docentes: olhares contemporâneos. Belo Horizonte: Autêntica, 2006.

Pimenta, Selma Garrido; Lima, Maria do Socorro Lucena. Estágio e docência. 2. ed. São Paulo: Editora Cortez, 2004.

Rodrigues, Micaías Andrade. A física do segundo ciclo do ensino fundamental em escolas da rede municipal de ensino do Recife. Dissertação (Mestrado em Educação) - Centro de Educação, Universidade Federal de Pernambuco, Recife, 2010.

Rodrigues, Micaías Andrade; Teixeira, Francimar Martins. Reflexões sobre a baixa procura pelo curso de física nas universidades federais de Pernambuco. In: Encontro Nacional de Pesquisa em Educação em Ciências, 7., 2009, Florianópolis. Atas... Florianópolis, VII ENPEC, v. 1, p. 1-11, 2009. Disponível em: <http://www.foco.fae. ufmg.br/pdfs/339.pdf>. Acesso em: 13 jan. 2011.

SAVIANi, Dermeval. Formação de professores: aspectos históricos e teóricos do problema no contexto brasileiro. Revista Brasileira de Educação, Rio de Janeiro: ANPEd; Campinas: Autores Associados, v. 14, n. 40, p. 143-155, 2009. Disponível em: <http://www.scielo. br/scielo.php?pid=S1413- 24782009000100012\&script=sci_arttext\&tlng=e!n>.Acesso em: 21 out. 2010 .

TARDIF, Maurice. Saberes profissionais dos professores e conhecimentos universitários: Elementos para uma epistemologia da prática profissional dos professores e suas consequências em relação à formação para o magistério. Revista Brasileira de Educação, Rio de Janeiro: ANPEd; Campinas: Autores Associados, n. 13, p. 5-24, jan./abr. 2000. 
Universidade Federal do Piauí. Resolução n. 84/95. Regulamenta o Estágio Supervisionado sob a forma de Prática de Ensino, componente dos Cursos de Licenciatura Plena da Universidade Federal do Piaui. Conselho de Ensino, Pesquisa e Extensão, 1995.

\section{SOBRE O AUTOR}

Micaías Andrade Rodrigues é mestre em educação pela Universidade Federal de Pernambuco (UFPE). Professor da Universidade Federal do Piauí (UFPI).

E-mail:micaias@ufpi.edu.br

Recebido em setembro de 2011

Aprovado em janeiro de 2012 


\section{MICAÍAS ANDRADE RODRIGUES}

\section{Quatro diferentes visões sobre o estágio supervisionado}

O estágio supervisionado de ensino é um momento muito importante para os estudantes durante os cursos de formação inicial de professores. Buscando compreender melhor esse momento, foi realizada uma pesquisa que objetivou compreender quatro 
diferentes visões sobre o estágio: a visão legal, a visão dos autores que estudam a temática e a visão dos professores colaboradores. Além de pesquisas bibliográficas e documentais, foram coletadas respostas de 72 alunos de dois cursos de licenciatura da Universidade Federal do Piauí(UFPI) que frequentavam diferentes disciplinas de estágio supervisionado e de 13 professores que receberam esses estagiários nas escolas. Podemos perceber que as diferentes visões encontram-se, de forma geral, em sintonia, demonstrando que as leis, os autores, os alunos e os professores nas escolas pensam de maneira semelhante. Cabe a nós, professores universitários, buscar maneira de aperfeiçoar o estágio supervisionado, melhorando a preparação dos futuros docentes para a atuação em sala de aula.

Palavras-chave: estágio supervisionado; formação de professores; licenciatura.

\section{Four different views on supervised practice}

The supervised teaching practice is a very important time for students during the courses of initial teacher education. Seeking to better understand this moment, we conducted a study that aimed to understand four different views on the supervised practice: the legal view, the sight of authors who study the subject' view, students and collaborating teachers. In addition to bibliographic and documentary research, we collected responses from 72 students in two undergraduate courses at UFPI, who attended different disciplines of supervised teaching practice, and of 13 teachers who received these trainees in schools. We realize that different views are overall in line, which evidences that the laws, authors, students and teachers in schools are likeminded. It behooves us, professors, to seek ways to improve the supervised training, improving the preparation of future teachers for working in classrooms.

Keywords: supervised teaching practice; teacher education; licensure undergraduate courses.

\section{Cuatro diferentes visiones sobre la práctica supervisada}

La práctica supervisada es un momento muy importante para los estudiantes durante los cursos de formación inicial del profesorado. Tratando de comprender mejor este momento, hemos realizado una encuesta que tuvo como objetivo comprender las cuatro perspectivas diferentes de la práctica: el punto de vista legal, según los autores que estudian el tema, el punto de vista de los estudiantes y de los profesores colaboradores. Además de la investigación bibliográfica y documental, las respuestas se obtuvieron de 72 estudiantes de las licenciaturas que asisten a las diferentes asignaturas de la práctica supervisada y trece maestros que reciben a esos alumnos en las escuelas. Nos damos cuenta de que diferentes puntos de vista se encuentran, en general, en sintonia, lo cual nos muestra que las leyes, los autores, los estudiantes y los maestros de las escuelas piensan de forma parecida. Nos corresponde, en cuanto académicos, buscar maneras de mejorar la práctica, mejorando la preparación de los futuros docentes para actuar en el aula.

Palabras clave: práctica supervisada; formación de profesores; licenciatura. 